\title{
COLONIC ADENOCARCINOMA WITH MALAKOPLAKIA OF COLON - A CASE REPORT
}

Chitrawati Bal Gargade ${ }^{1}$, Abhay Yashwant Desai²

\section{HOW TO CITE THIS ARTICLE:}

Chitrawati Bal Gargade, Abhay Yashwant Desai. "Colonic Adenocarcinoma with Malakoplakia of Colon - A Case Report". Journal of Evolution of Medical and Dental Sciences 2015; Vol. 4, Issue 74, September 14; Page: 12955-12959, DOI: 10.14260/jemds/2015/1868

\begin{abstract}
The gastrointestinal tract is the most common site for malakoplakia outside the urinary tract. A variety of conditions co-exists with malakoplakia including inflammatory bowel disease, systemic lupus erythematosus, immunodeficiency and tuberculosis. Rarely, it is associated with colonic adenocarcinoma or adenomas. We report a case of malakoplakia in association with colonic adenocarcinoma.
\end{abstract}

KEYWORDS: Malakoplakia, Michaelis- Gutmann bodies, Colon; Adenocarcinoma colon.

INTRODUCTION: Malakoplakia, an inflammatory condition first described by Michaelis and Gutmann in 1902.[1] It is characterised by collections of histiocytes containing laminated, calcified MichaelisGutmann inclusion bodies. Malakoplakia frequently involves the urinary tract, gastrointestinal tract being the second most common site. ${ }^{22}$ In the intestine, it occurs most frequently in the descending colon, sigmoid, and rectum; it is found less commonly in the terminal ileum, stomach, appendix, and caecum. Colorectal malakoplakia is usually associated with adenocarcinoma. ${ }^{[3-5]}$ In such conditions; the tumour may be over staged and lead to extensive surgery. We describe a case of malakoplakia of colon in association with adenocarcinoma for its rarity and clinical significance.

CASE REPORT: A 70-years-old man was admitted to the hospital with history of abdominal pain and per rectal bleeding since one month. Patient is a known case of diabetes, hypertension and ishaemic heart disease. He was diagnosed as having pulmonary tuberculosis seven years back and completed anti-tuberculosis treatment.

On physical examination the patient had hypogastric tenderness and guarding and a $4 \mathrm{~cm}$ mass was palpable in the left iliac fossa. CT scan of abdomen and pelvis revealed irregular, circumferential thickening of the wall of sigmoid colon with extra serosal spread and pericolic region suggestive of malignant neoplasm of the sigmoid colon. Also seen focal disruption of colonic wall along its anterior aspect which is communicating with large, thick walled irregular, hypoattenuated fluid collection, the collection is in between the anterior abdominal wall anteriorly and involved sigmoid colon posteriorly suggestive of colonic perforation with fistula and abscess formation.

On gross examination specimen consisted of $20 \mathrm{~cm}$ of colon showing asymmetrical thickening involving $6 \mathrm{~cm}$ of bowel, partly in anterior quadrant and partly in posterior quadrant. An ill-defined mass measuring $9.5 \times 5.5 \times 5 \mathrm{~cm}$ was seen arising from the bowel wall. The mass on cut section showed yellow necrotic and whitish fibrosed areas.

The histological examination showed well differentiated adenocarcinoma of colon invading the muscularis propria with serosal tumour deposits. Microphotograph shows adenocarcinoma and histiocytes. (Fig. 1) Sixteen lymph nodes dissected do not show any histiocytic infiltration or tumour deposits. There was no evidence of nodal, intravascular, or lymphatic spread. 
Multiple sections from yellowish mass show sheets of histiocytes admixed with lymphocytes, extending into pericolic fat. (Fig. 2) These histiocytes had granular cytoplasm and contained MichaelisGutmann bodies. (Fig. 3) (Fig. 4)Positive immunohistochemical staining with CD 68 confirmed their histiocytic lineage. No organisms were identified in Gram stain and, ZN stain was negative for Acid Fast Bacilli.

DISCUSSION: Malakoplakia is a rare, chronic, granulomatous inflammatory disease, which was first described by Michaelis and Gutmann in 1902. Von Hansemann first described it in a necropsy study in 1903.[6] when he found a macrophagic infiltrate with PAS positive intracytoplasmic inclusion bodies in the urinary bladder of a 66-years-old man who died of pulmonary tuberculosis. He coined the term malakoplakia, which means "Soft plaque". Posterior ultrastructural studies showed that these inclusion bodies were composed of mineralized organic material arranged in concentric layers surrounded by a simple, lysosomic-type, membrane Malakoplakia associated with colorectal adenocarcinoma.[7]

Malakoplakia occurs most frequently in the genitourinary tract but is also found in many other organs like gastrointestinal tract, lungs, liver, pancreas, lymph nodes, adrenal gland, skin, salivary glands, and brain, with the gastrointestinal tract being the second most-common site.[8] Colonic malakoplakia was first described by Terner and Lattes in 1965.[9] and occurs in conjunction with tumors and non-tumoral conditions.[10,11] Most of these had a coexistent colonic adenocarcinoma, similarly to our case.

Mean age of patients affected by malakoplakia is around 45 to 50 years and males are more affected than females. Paediatric cases are rare. Only few pediatric cases are reported presenting as multiple polyps involving colon and rectum.[12]

\section{Endoscopically it appears in Three Patterns.[13]:}

1. Isolated sessile or polypoid masses in the rectosigmoid colon; the lumen may be narrowed suggesting a malignant stricture. The inflammatory process may be transmural, resembling Crohn's disease.

2. Diffuse involvement of the entire colon with either polypoid or serpiginous lesions or diffuse ulceration. This form is often present in patients with compromised immunity Including renal transplant recipients, immunosuppressive drug therapy, and hereditary immunodeficiency.

3. A mass-like lesion occurring alone or in association with cancer of the colon or an adenomatous polyp.

An increasing number of cases have been correlated with immune suppression. Most of the patients with malakoplakia suffer from cancer or are immunocompromised due to AIDS, tuberculosis, renal transplantation, or chemotherapy. Prolonged steroidal therapy in neoplastic patients has been incriminated in the development of peritumoral malakoplakia in some cases.[14]

\section{Although the exact cause of malakoplakia is not clear, three possible mechanisms have been suggested:}

1. Role of bacteria like Escherichia, Mycobacterium tuberculosis, Proteus mirabilis and Staphylococcus aureus.

2. Abnormal or altered immune response. 


\section{CASE REPORT}

3. Abnormal macrophage response because of defective lysosomal function. ${ }^{[4]}$ This is due to guanosine monophosphate dehydrogenase and beta-glucuronidase deficiency which alters the microtubular and lysosomal function leading to incomplete elimination of bacteria from macrophages.[2]

The gross appearance of malacoplakia varies from unifocal, multiple, and even widespread nodular lesions to a large, soft, yellow mass, usually covered by intact mucosa that may be centrally depressed.

Malakoplakia is characterized by aggregates of histiocytes with abundant eosinophilic cytoplasm known as von Hansemann cells, intermingled with lymphocytes, plasma cells and neutrophils. Finding the well-known Michaelis-Gutmann bodies is diagnostic for malakoplakia. Michaelis-Gutmann bodies stain blue with Haematoxylin-eosin and are positive for calcium and iron with the von Kossa stain and the Perl's stain, respectively. The histiocytes stain positively for the CD68 antibody. Electron microscopy of histiocytes shows phagolysosomal inclusions comprising vesicles, electron dense bodies, membranous lamellae and the crystalline M-G bodies.[15]

In our case, basophilic stained MG bodies on Haematoxylin and eosin stain demonstrates PAS positivity on PAS stain and diffuse cytoplasmic positivity of CD68.

The early stages of malakoplakia should be differentiated from Whipple disease, atypical mycobacterial tuberculosis, histiocytic storage disorders, and fungal infections. ${ }^{[2]}$ In Whipple disease, the cytoplasmic granules are Sudan black positive whereas they are negative in malakoplakia. Special stains may help in excluding tuberculosis and fungal infections. In the present case the Gram and ZiehlNeelsen stains failed to reveal any bacteria.

In our case of malakoplakia, two debilitating diseases; pulmonary tuberculosis and adenocarcinoma of colon might have affected immunity leading to peritumoral malakoplakia.

Erroneous clinical upstaging of carcinoma because of coexisting malakoplakia involving lymph nodes or other organs is a possible clinical pitfall. Hanseman histiocytes can mimic adenocarcinoma cells in frozen sections. A helpful clue for the correct diagnosis is the presence of Michaelis- Gutmann bodies which are not seen in mucin vacuoles.

The coincidence of malakoplakia with adenocarcinoma in our case makes it difficult for us to ascertain the exact location of wall infiltration by the neoplasm. We are presenting this case because it presented as a pseudotumoral appearance not only on clinical and radiological findings, but also in the surgical room and on the pathological gross examination

Furthermore, there are some cases of malakoplakia that also affect regional lymph nodes or even other abdominal organs. In these examples the inflammation may give the false impression of metastatic seed.[16] The draining lymph nodes were involved by malakoplakia to varying degrees in all cases reported by Pillay K. ${ }^{[17]}$ However lymph nodes showed metastatic deposits in three cases but no malakoplakia was detected in lymph nodes in any case studied by Leire Andrés.[3] and others. The lymph nodes dissected in the present case do not show any histiocytic infiltration or tumour deposit.

Malakoplakia associated with adenocarcinoma of the colon and rectum does not have prognostic significance in cases of colonic carcinoma.[18] However it is important to be aware that the diagnosis of malakoplakia may indicate an associated malignancy. 
CONCLUSION: Our case may serve as a reminder of the clinical significance of malakoplakia coexisting with colonic adenocarcinoma, which increased the risk of over-staging the tumor and over-treating the patient.

\section{REFERENCES:}

1. Michaelis L, Gutmann C. Uber Einschliisse in Blastentumoren.Z Klin Med 1902; 47:208-15.

2. Yousef GM, Naghibi B. Malakoplakia outside the urinary tract. Arch Pathol Lab Med. 2007; 131:297-300.

3. Leire Andres,Leire Etxegarai,Jos I. Lopez,Laura Oleaga,Francisco J.Bibao, Cosome Ereno. Malakoplakia associated with colorectal adenocarcinoma. Ann Saudi Med 2005:25:50-52

4. Karasavvidou F, Potamianos SP, Barbanis S, Stathakis E, Psychos A, Kapsoritakis AN, et al. Malakoplakia of the colon associated with colonic adenocarcinoma diagnosed in colonic biopsies. World J Gastroenterol 2007;13:6109-11

5. L.Edmund, Mohammed. Colonic Carcinoma associated with malakoplakia. West Indies medical journal 2014; 63:664-6

6. Von Hansemann D. Uber Malakoplakia der Harnblase. Virchows Arch 1903;173:302-8.

7. Ghadially FN. Ultrastructural Pathology of the Cell and Matrix. 4th Edition, vol 2. Boston: Butterworth-Heinemann 1997:720-723

8. Alavian SM, Raissi SF, and Kamalian F. Malakoplakia of the colon: A case report and literature review. MJIRJ 2001; 15:179-82

9. Terner .IY. Lattes R: Malakoplakia of colon and retro peritoneum. Am J Clin Pathol 1965; 44:20

10. Rizzo E, Sandmeier D, Hack I, Matter M, Bouzourene H. Malakoplakia and colonic adenoma: a rare association. Ann Diagn Pathol 2004;8:364-6

11. Asiyanbola B, Camuto P, Mansourian V. Malakoplakia occurring in association with colon carcinoma. J Gastrointest Surg 2006;10:657-661

12. Divya P, Crasta JA. Pediatric malakoplakia of colon: A report of two cases. Pediatr Surg Int 2010; 26:323-5.

13. McClure .I: Malakoplakia of the gastrointestinal tract. Postgrad Med .1981;57:95-103

14. Bates AW, Dev S, Baithum SI. Malakoplakia and colorectal adenocarcinoma. Postgrad Med J 1997; 73:171-3.

15. Sinclair-Smith C, Kahn LB, Cywes S. Malakoplakia in childhood. Case report with ultrastructural observations and review of the literature. Arch Pathol 1975;99:198-203

16. Matter M, Gygi C, Gillet M, Gebhard S, Bouzourene H. Malakoplakia simulating organ invasion in a rectosigmoid adenocarcinoma. Dis Colon Rectum 2001; 44: 1371-5

17. Pillay K1, Chetty R. Malakoplakia in association with colorectal carcinoma: a series of four cases. Pathology 2002; 34:332-5.

18. Sandmeier D, Gulliou L.Malacoplakia and adenocarcinoma of the caecum- a rare association. J.Clin.Pathol 1993; 46:959-60. 


\section{CASE REPORT}

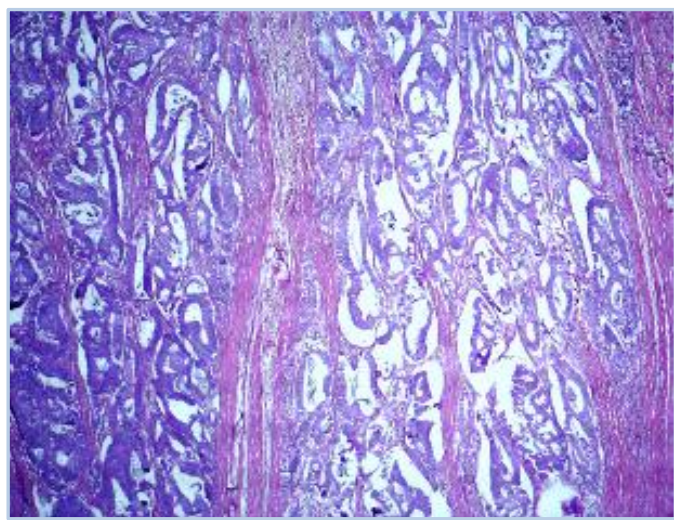

Fig. 1: Adenocarcinoma colon (40X H\&E)

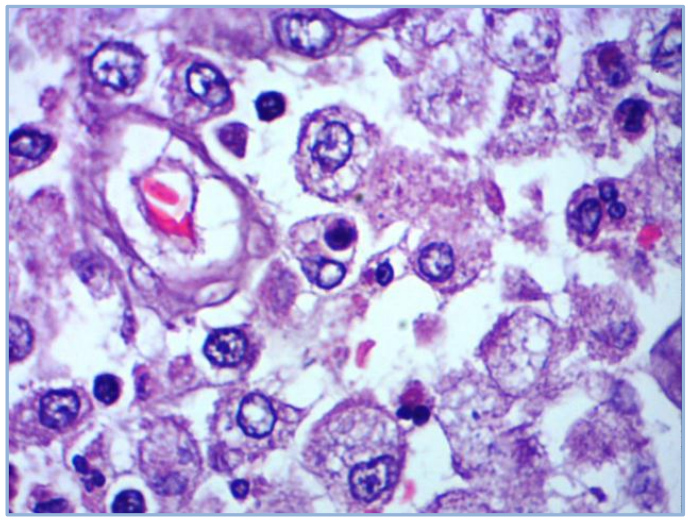

Fig. 3: Histiocytes with Michaelis Gutmann bodies ( $\mathrm{H}$ and E, $1000 \mathrm{x}$ )

\section{AUTHORS:}

1. Chitrawati Bal Gargade

2. Abhay Yashwant Desai

\section{PARTICULARS OF CONTRIBUTORS:}

1. Associate Professor, Department of Pathology, BKL Walawalkar Rural Medical College, Derwan A/P Sawarde, Taluka-Chiplun, District-Ratnagiri.

2. Assistant Professor, Department of Surgery, BKL Walawalkar Rural Medical College, Derwan A/P Sawarde, Taluka-Chiplun, District-Ratnagiri.

FINANCIAL OR OTHER COMPETING INTERESTS: None

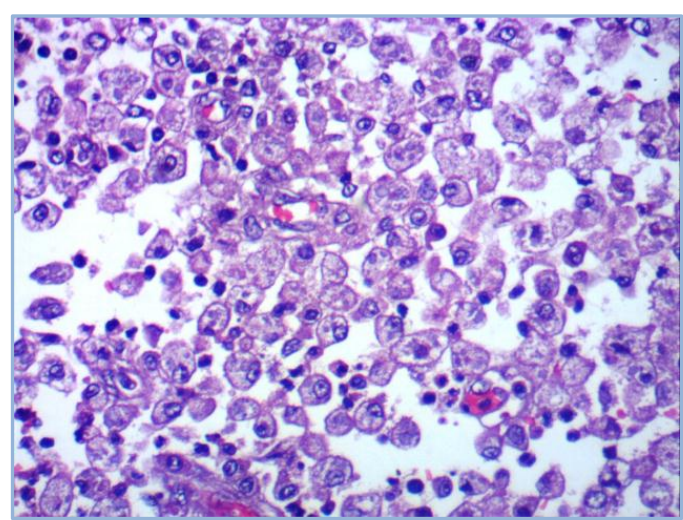

Fig. 2: Microphotograph showing sheets of foamy histiocytes. (40X H\&E)

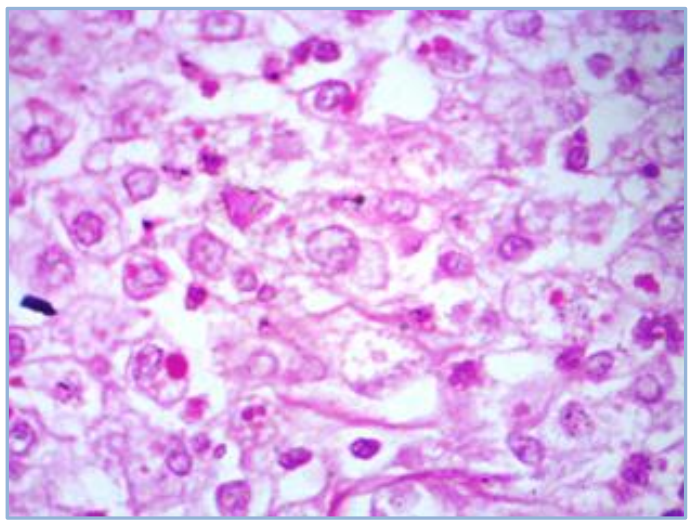

Fig. 4: Michaelis - Gutmann bodies staining magenta by PAS (1000X)

\section{NAME ADDRESS EMAIL ID OF THE CORRESPONDING AUTHOR:}

Dr. Chitrawati Bal Gargade, Department of Pathology, BKL Walawalkar Rural Medical College, Derwan A/P Sawarde,

Taluka-Chiplun, District-Ratnagiri-415606, Maharashtra.

E-mail: chitragargade@yahoo.com

Date of Submission: 26/08/2015. Date of Peer Review: 27/08/2015. Date of Acceptance: 07/09/2015. Date of Publishing: 14/09/2015. 